\title{
Análise da influência da sazonalidade na eficiência da estação de tratamento de esgoto do município de Caldas Novas/GO
}

O município de Caldas Novas possui um dos maiores mananciais hidrotermais aproveitáveis do mundo e devido a sua urbanização rápida e desordenada, resultado do investimento em turismo, desenvolveu vários problemas ambientais na sua infraestrutura, por esta não ter acompanhado o crescimento populacional ampliando de forma significativa a produção de esgoto provocando casos de problemas de extravasamento do esgoto por deficiência da capacidade de tratamento. Desta forma objetivou-se avaliar a variação da eficiência da estação de tratamento de esgoto do município e a interferência das sazonalidades por meio da análise dos parâmetros pH, Temperatura, DBO, DQO e Sólidos Suspensos aplicando a análise de variância e teste de Tukey e ainda verificar se os parâmetros estão dentro dos padrões aceitáveis pela legislação. De acordo com as análises das médias do período para cada parâmetro, observou-se que há grande variabilidade entre eles, indicando influência da sazonalidade. Ao que diz respeito a eficiência do tratamento, apresentou-se satisfatória e com valores dentro dos limites exigidos pela legislação estadual, Decreto $n^{\circ}$. 1.745/1979 e legislação federal Resolução CONAMA 430/2011. Por meio da análise da relação DQO/DBO, nota-se que não houve eficiência na remoção de matéria biodegradável. Os SST apresentaram boa eficiência e dentro daquilo que se estima na literatura.

\section{Analysis of the influence of seasonality on the efficiency of the sewage treatment plant in the city of Caldas Novas/GO}

\begin{abstract}
The municipality of Caldas Novas has one of the largest usable hydrothermal vents in the world and due to its rapid and disordered urbanization, the result of investment in tourism, which has developed several environmental problems in its infrastructure, as it has not kept up with population growth, previous form of sewage production causing cases of sewage overflow problems due to deficient treatment capacity. Thus, the objective was to evaluate the variation in the efficiency of the municipal sewage treatment plant and the interference of seasonality through the analysis of the parameters $\mathrm{pH}, \mathrm{Temperature,} \mathrm{BOD,COD}$ and Suspended Solids applying the analysis of variance and Tukey test and also check if the parameters are within the standards acceptable by law. According to the analysis of the averages of the period for each parameter, it was observed that there is great variability between them, indicating the influence of seasonality. Regarding the efficiency of the treatment, it was satisfactory and with values within the limits required by the state legislation, Decree no. 1,745/1979 and federal legislation CONAMA Resolution 430/2011. Through the analysis of the COD/BOD ratio, it is noted that there was no efficiency in removing biodegradable matter. The SST showed good efficiency and within what is estimated in the literature.
\end{abstract}

Keywords: Sanitary sewage; Release standards; Floating population.

Topic: Engenharia Ambiental

Reviewed anonymously in the process of blind peer.
Received: 04/03/2021

Approved: 24/03/2021
Ítala Tainá Alves de Souza (iD

Instituto Federal Goiano, Brasil

http://lattes.cnpq.br/7386091115085545

http://orcid.org/0000-0002-7599-0980

italataina04@gmail.com

Bruno Botelho Saleh (iD

Instituto Federal Goiano, Brasil

http://lattes.cnpq.br/2279628061058840

http://orcid.org/0000-0002-6790-0690

bruno.saleh@ifgoiano.edu.br

Bruno de Oliveira Costa Couto

Instituto Federal Goiano, Brasil

http://lattes.cnpq.br/7679222927811979

http://orcid.org/0000-0003-0319-3293

bruno.couto@ifgoiano.edu.br
Referencing this:

SOUZA, I. T. A.; SALEH, B. B.; COUTO, B. O. C.. Análise da influência da sazonalidade na eficiência da estação de tratamento de esgoto do município de Caldas Novas/GO. Revista Ibero Americana de Ciências Ambientais, v.12, n.3, p.349-361, 2021. DOI:

http://doi.org/10.6008/CBPC2179-6858.2021.003.0029 


\section{INTRODUÇÃO}

As atividades de saneamento têm papel preponderante na qualidade de vida dos centros urbanos, através do fornecimento de água, a coleta, o tratamento e a disposição adequada dos esgotos domésticos que, além de colaborarem para a saúde da comunidade, contribuem para a conservação ambiental.

A sazonalidade é caracterizada por um conjunto de variações periódicas que podem ocorrer ao longo das horas do dia, ao longo dos dias da semana e dos meses do ano. De acordo com Nuvolari (2003), o esgoto sanitário é formado a partir da utilização de água de abastecimento, sendo o volume de efluente gerado proporcional à quantidade de água consumida pela população e esta quantidade, segundo explica Oliveira (2014), é influenciada por variações sazonais consequentes das estações do ano como as condições climáticas, o cotidiano e as atividades da população e a flutuação populacional influenciada pelo turismo.

Associados ao clima, os principais responsáveis pelos padrões sazonais e oscilações nos volumes de água requeridos são a temperatura, umidade e precipitação que influenciam o consumo de água e a consequente geração de esgoto de forma que, conforme aumenta a temperatura aumenta-se o consumo, quando a umidade é baixa, como ocorre em regiões mais secas, o consumo é maior, já a presença de chuvas afeta diretamente o consumo, reduzindo-o drasticamente na sua ocorrência (BARBIERO et al., 2011).

A sazonalidade populacional, também denominada população flutuante, é uma variação comum da população que ocorre ao longo do ano em localidades turísticas e de veraneio, atingindo valores mais elevados durante as férias e feriados importantes e, segundo a NBR 9648 - Estudo de concepção de sistemas de esgoto sanitário - (ABNT, 1986), se refere à população que, proveniente de outras comunidades, se transfere ocasionalmente para área considerada, impondo ao sistema de esgoto uma contribuição individual análoga à da população residente.

Localizado no Estado de Goiás, o município Caldas Novas, objeto deste estudo, possui um dos maiores mananciais hidrotermais aproveitáveis do mundo, motivo ao qual levou a grande procura pela região, levando a partir da década de 70 , ao alto investimento em turismo, resultando no aumento da população residente de forma intensa, consequência do crescimento econômico que atraiu para a cidade um número muito grande de migrantes, e com o aumento cada vez maior da população flutuante atraída pelo turismo (PRADO et al., 2008).

A cidade de Caldas Novas, devido a sua urbanização rápida e desordenada, desenvolveu vários problemas ambientais na sua infraestrutura, por esta não ter acompanhado o crescimento populacional, abrindo caminho para uma má ocupação do solo. O expansionismo do município ampliou de forma significativa a produção de esgoto (COSTA et al., 2007), provocando problemas de extravasamento do esgoto na Estação de Tratamento de Esgoto municipal por deficiência da capacidade do sistema de tratamento, incidindo diretamente no corpo receptor, segundo explicam Costa et al. (2012).

Desta forma, no presente estudo, objetivou-se avaliar a variação da eficiência total da estação de tratamento de esgoto do município de Caldas Novas - GO com base nas sazonalidades turística e climática, por meio da análise dos parâmetros pH, temperatura, DBO, DQO e SST, bem como, se estes estão dentro dos 
padrões aceitáveis pela legislação.

\section{MATERIAIS E MÉTODOS}

\section{Localização e Caracterização da Área de Estudo}

O município de Caldas Novas - GO (Figura 1), está localizado no sudeste do Estado de Goiás e se encontra à 177 km de Goiânia, capital do Estado e 280 km de Brasília, capital do País e possui população residente de 89.087 habitantes e economia voltada para o turismo.

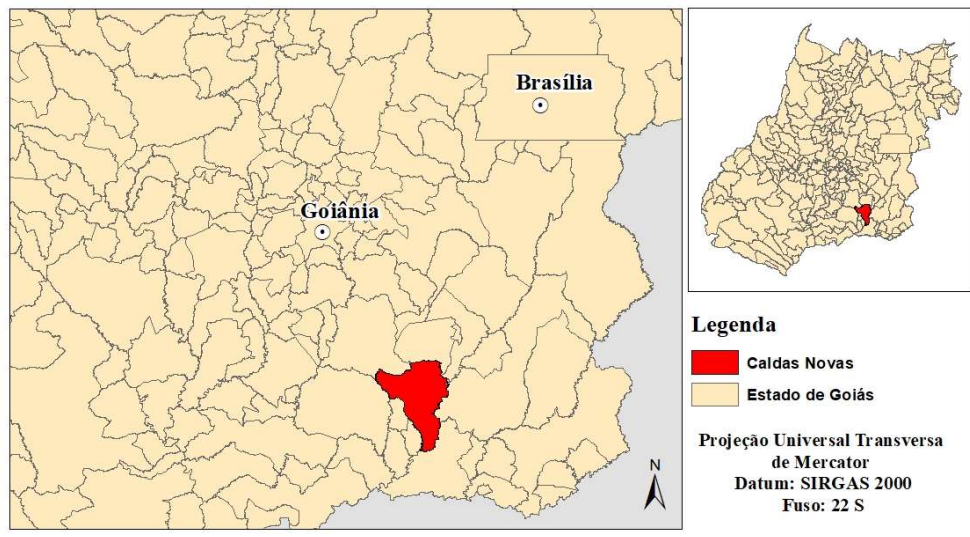

Figura 1: Mapa de localização do município de Caldas Novas - GO.

Sua sazonalidade turística é bastante peculiar, atraindo pessoas de várias regiões do país, e está varia em função de diversos fatores como os ciclos de atividades econômicas, as variações do clima, férias escolares, as temporadas de festas e feriados (ROCHA, 2003).

Devido a sua localização, o clima do município predominante é tropical chuvoso de savana, quente e úmido, com chuvas de verão. De acordo com o site Climatempo (2018, citado por DEMAE, 2018), a precipitação média anual é de $1.418 \mathrm{~mm}$ e o período chuvoso acontece entre outubro e março, com totais médios de 269 mm no mês de janeiro e os meses de mais frio são maio, junho e julho.

A estação recebe contribuição de alguns efluentes de indústrias hoteleiras, cerca de 41 economias cadastradas até julho de 2018, que passam por um tratamento prévio em suas estações de tratamento lançam seus efluentes na rede municipal, porém não existe um decreto regulamentando o padrão do efluente líquido proveniente dessas economias para que este possa ser lançado na rede coletora municipal de esgoto (DEMAE, 2018).

A estação de tratamento de esgoto do município, objeto deste estudo, é operada pelo Departamento Municipal de Água de Esgoto - DEMAE e está localizada no perímetro urbano do município, no bairro Estância dos Buritis, próxima ao aeroporto, com as seguintes coordenadas geográficas: Latitude 17ㄴ3'59" Sul e Longitude 48으'21" Oeste.

A ETE possui uma área total de 19ha e foi reinaugurada em fevereiro de 2014. Esta foi projetada com uma vazão de $100 \mathrm{~L} \mathrm{~s}^{-1}$ e atende cerca de 70.000 habitantes, o que corresponde a 82,44\% da população total residente. O efluente tratado é lançado no Ribeirão Caldas, localizado a aproximadamente $95 \mathrm{~m}$ da estação.

A unidade conta com tratamento preliminar composto por gradeamentos, caixa de areia e caixa de 
escuma, posterior tratamento secundário por processo biológico realizado pelo Reator Anaeróbio de Fluxo Ascendente (RAFA) seguido de lagoas de estabilização, como mostra a Figura 2.

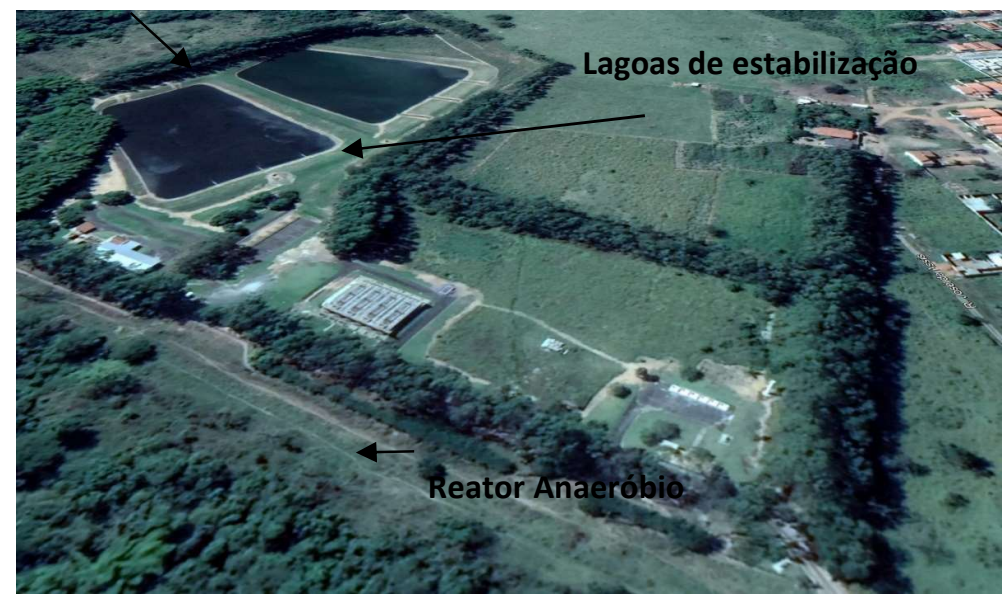

Figura 2: Estação Tratamento de Esgoto de Caldas Novas - GO vista por satélite. Fonte: Google Earth (2019).

O sistema (Figura 3) contempla em sua configuração com quatro reatores anaeróbios e duas lagoas anaeróbias em série, com os principais parâmetros de projeto apresentados na tabela 1.

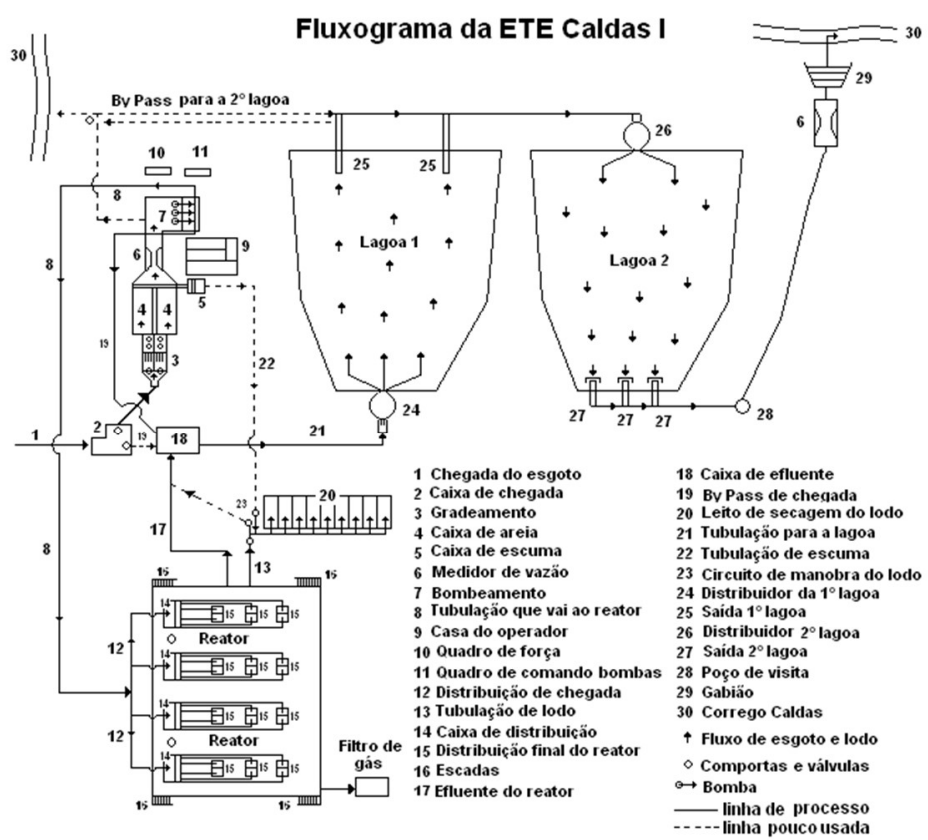

Figura 3: Fluxograma do sistema da Estação de Tratamento de Esgoto de Caldas Novas - GO. Fonte: DEMAE (2019).

Tabela 1: Parâmetros de projeto Estação de Tratamento de Esgoto de Caldas Novas - GO.

\begin{tabular}{lll}
\hline Parâmetros de Projeto & Reatores anaeróbios & Lagoas anaeróbias \\
\hline Profundidade Útil & $4,5 \mathrm{~m}$ & $5 \mathrm{~m}$ \\
Volume Útil & $2.000 \mathrm{~m}^{3}$ & $30.000 \mathrm{~m}^{3}$ \\
Tempo de Detenção Hidráulico & 6 horas & 3,5 dias \\
\hline
\end{tabular}

Fonte: DEMAE (2019).

A princípio as lagoas foram projetadas como lagoa aerada e lagoa de decantação, porém atualmente não existem aeradores instalados na lagoa. 


\section{Coleta dos Dados}

Os dados foram concedidos pelo Departamento Municipal de Água e Esgoto de Caldas Novas DEMAE, por meio de planilha das análises de monitoramento periódicos.

Os dados concedidos das análises físico-químicas dos parâmetros Vazão, Temperatura, pH, DBO, DQO e Sólidos Suspensos referem-se ao monitoramento mensal do afluente e efluente final do sistema, avaliados no período de janeiro de 2016 a dezembro de 2018.

As análises são realizadas por um laboratório terceirizado através de amostras colhidas por membros da ETE e colocadas em frascos para preservar as amostras seguindo as normas de coleta e preservação de amostras segundo a NBR 9.898 - Preservação e técnicas de amostragem de efluentes líquidos e corpos receptores (ABNT, 1987).

As quantidades de dados dos resultados das análises referentes aos anos variam conforme mostra a tabela 2.

Tabela 2: Quantidade de dados coletados no período de 2016 a 2018.

\begin{tabular}{lllllll}
\hline Ano & Vazão & Temp & PH & DBO & DQO & SS \\
\hline 2016 & 12 & 12 & 12 & 25 & 25 & 25 \\
2017 & 12 & 12 & 12 & 18 & 18 & 18 \\
2018 & 12 & 12 & 12 & 25 & 25 & 25 \\
\hline
\end{tabular}

Fonte: DEMAE (2019).

Todas as análises foram realizadas com procedimento analítico conforme metodologia de Standard Methods for Examination of Water and Wastewater (APHA et al., 2005).

\section{Análise dos Dados}

Os resultados dos parâmetros foram obtidos através de estatística descritiva, por meio do cálculo da análise de variância (ANOVA) e aplicando o teste de Tukey.

A estatística foi aplicada para comparação entre os dados dos três anos no período em estudo e entre afluente e efluente. Para os parâmetros Vazão e Temperatura, também foi feita a comparação entre os dados do período seco e o período chuvoso.

Para os dados que obtiveram variação muito alta, a fim de demonstrar a variabilidade entre os resultados e consequentemente a confiabilidade entre eles, foi calculado o coeficiente de variação (CV) que indica o grau de variação e serve para dizer o quanto os valores dos quais se extraiu a média são próximos ou distantes da própria média. O CV pode ser definido como o desvio padrão expresso em porcentagem da média e é obtido pela equação 1:

$$
\mathrm{CV}(\%)=\frac{\mathrm{S}}{\mathrm{X}} \times 100
$$


a cada parâmetro e foi obtida através da equação 1, conforme estabelecido por Von Sperling (2005).

$\mathrm{E}(\%)=\frac{\mathrm{Ca}-\mathrm{Ce}}{\mathrm{Ca}} \times 100$

(2)

Todos os cálculos estatísticos foram processados com o auxílio software Excel, de modo a facilitar a comparação dos mesmos com as referidas normas.

Para a avaliação da eficiência da estação de tratamento em estudo foi feita uma comparação entre as médias dos parâmetros selecionados e os valores máximos previstos em normas vigentes quanto ao lançamento de efluentes em corpos receptores, tanto a nível federal (Resolução 430/2011 - CONAMA) como também a nível estadual (Decreto $\left.n^{\circ} .1 .745 / 1979\right)$.

Para os parâmetros não preconizados pela legislação quanto aos limites de lançamento, buscou-se comparar com dados registrados na literatura em termos de eficiência.

\section{RESULTADOS E DISCUSSÃO}

\section{Vazão}

Os dados obtidos pelo monitoramento da vazão afluente a ETE, no período em estudo, indica que o sistema opera atualmente com uma vazão média de aproximadamente $261,61 \mathrm{~m}^{3} / \mathrm{h}$, referente a $72,5 \%$ da sua vazão de projeto, isto é, operando dentro de seu limite.

O gráfico (Figura 3) mostra a variação da vazão afluente, todavia, como pode ser observado na Tabela 3, os coeficientes de variação dos três anos são baixos, expressando homogeneidade entre os dados, ou seja, não há muita variação. O que indica que está é resultante da sazonalidade climática, a qual afeta o consumo de água e consequente geração de esgoto, além das chuvas, que, ao infiltrarem no solo e depois nas redes coletoras, contribuem no volume de esgoto afluente, conforme explica Hanai et al. (1997). Porque, mesmo a ETE recebendo efluente de alguns hotéis da região central, segundo consta no Plano de Saneamento do município, estes equivalem a 0,1\% das ligações residenciais, não sendo significativo (DEMAE, 2018).

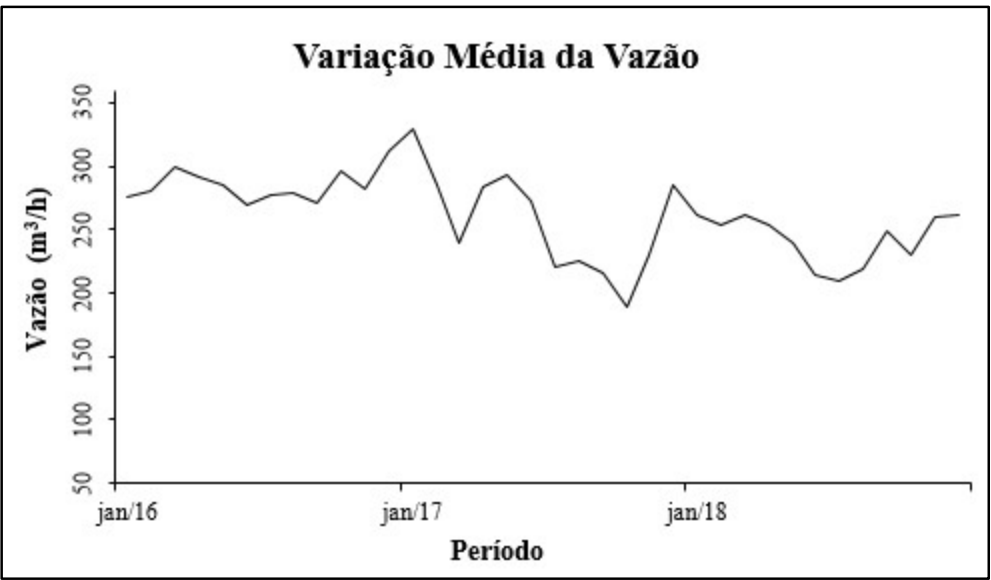

Figura 4: Variação da vazão afluente durante o Monitoramento da ETE, no período de janeiro de 2016 a dezembro de 2018. 
Tabela 3: Análise de Variância e Teste de Tukey da vazão média afluente a ETE de Caldas Novas/GO.

\begin{tabular}{ll|ll}
\hline Analise de variância & Vazão $\left(\mathbf{m}^{\mathbf{3}} \mathbf{h}\right)$ & Teste de Tukey a 5\% & CV (\%) \\
\hline GL resíduo & 33 & Vazão (2016): 284,85 a & 4,46 \\
F tratamentos & $7,40^{* *}$ & Vazão (2017): 255,44 b & 16,19 \\
Média geral & 261,61 & Vazão (2018): 242,75 b & 8,21 \\
Desvio padrão & 27,51 & & \\
Diferença mínima significativa (5\%) & 27,56 & & \\
Coeficiente de variação (CV) (\%) & 10,54 & & \\
\hline
\end{tabular}

Nível de significância: $1 \% * *, 5 \% *$. (x) Mais de um valor.

A análise das médias anuais mostra que a vazão do ano de 2016 é estatisticamente diferente da vazão dos anos de 2017 e 2018. Além disso, a vazão de 2016 é maior do que a dos outros anos, isso pode ser explicado pela quantidade de chuva nestes anos, onde, segundo dados coletados pela estação meteorológica da AMAT - Associação das Empresas Mineradoras das Águas Termais de Goiás, foram de 2.413,4mm em 2016, 1.045,07mm em 2017 e, devido a problemas ao acesso da estação foi registrado apenas a média de $286,6 \mathrm{~mm}$ do ano de 2018.

Por meio da análise de comparação entre as médias do período chuvoso da região (outubro a março) e o período seco (abril a setembro), apresentado na Tabela 4, pode-se comprovar a influência da sazonalidade do clima, pois, embora estatisticamente estas sejam iguais, a vazão afluente no período chuvoso é maior.

Tabela 4: Análise de Variância e Teste Tukey da vazão afluente a ETE de Caldas Novas/GO nos períodos seco e chuvoso dos anos de 2016 a 2018.

\begin{tabular}{|c|c|}
\hline Análise de variância & Vazão (m³/h) \\
\hline GL resíduo & 34 \\
\hline F tratamentos & 1,96 \\
\hline Média geral & 261,61 \\
\hline Desvio padrão & 31,71 \\
\hline Diferença mínima significativa (5\%) & 21,48 \\
\hline Coeficiente de variação (CV) (\%) & 12,15 \\
\hline \multicolumn{2}{|l|}{ Teste de Tukey a 5\% } \\
\hline Período seco & $253,61 \mathrm{a}$ \\
\hline Período chuvoso & $268,41 \mathrm{a}$ \\
\hline
\end{tabular}

Nível de significância: $1 \% * *, 5 \% *$. (x) Mais de um valor.

pH e Temperatura

$\mathrm{O} \mathrm{pH}$ (tabela 5) e a temperatura (tabela 6), dentre os parâmetros analisados, foram os que obtiveram menor variabilidade se apresentando praticamente estáveis.

Tabela 5: Análise de Variância e Teste de Tukey do pH do efluente da ETE de Caldas Novas/GO.

\begin{tabular}{llll}
\hline Análise de variância & $\mathbf{p H}$ entrada & $\mathbf{p H}$ saída & $\mathbf{p H}$ \\
\hline GL resíduo & 33 & 33 & 70 \\
F tratamentos & 0,56 & 1,72 & $20,05^{* *}$ \\
Média geral & 6,99 & 6,82 & 6,91 \\
Desvio padrão & 0,21 & 0,10 & 0,16 \\
Diferença mínima significativa (5\%) & 0,21 & 0,10 & 0,08 \\
Coeficiente de variação (CV) (\%) & 2,98 & 1,49 & 2,36 \\
\hline Teste de Tukey a 5\% & & & \\
\hline pH (2016) & 7,00 a & 6,84 a & Afluente: 6,99 a \\
pH (2017) & $7,03 \mathrm{a}$ & $6,78 \mathrm{a}$ & Efluente: $6,82 \mathrm{~b}$ \\
pH (2018) & $6,94 \mathrm{a}$ & $6,84 \mathrm{a}$ & \\
\hline
\end{tabular}

Nível de significância: $1 \% * *, 5 \% *$. Médias com letras iguais entre colunas não se diferem estatisticamente. 
Tabela 6: Análise de Variância e Teste de Tukey da Temperatura do efluente da ETE de Caldas Novas/GO.

\begin{tabular}{lll}
\hline Análise de variância & $\mathbf{T}\left({ }^{\circ} \mathbf{C}\right)$ & $\mathbf{T}\left({ }^{\circ} \mathbf{C}\right)$ \\
\hline GL resíduo & 33 & 34 \\
F tratamentos & 1,59 & $20,02 * *$ \\
Média geral & 27,89 & 27,89 \\
Desvio padrão & 0,58 & 0,47 \\
Diferença mínima significativa (5\%) & 0,58 & 0,32 \\
Coeficiente de variação (CV) (\%) & 2,07 & 1,70 \\
\hline Teste de Tukey a 5\% & & \\
\hline Temperatura (2016) & 27,65 a & Período seco \\
Temperatura (2017) & 27,99 a & Período chuvoso \\
Temperatura (2018) & 28,03 a & 27,54 b \\
\hline
\end{tabular}

Nível de significância: 1\%**,5\%*. Médias com letras iguais entre colunas não se diferem estatisticamente.

Referente ao $\mathrm{pH}$ afluente, este se mantém próximo a neutralidade com média de 6,99. Embora haja variação, o CV indica há baixa variabilidade, o que é de suma importância para o desempenho do sistema, uma vez que elevadas variações do pH prejudicam o tratamento biológico afetando o crescimento dos microrganismos.

$\mathrm{O}$ pH efluente também apresentou baixa variação, com média de 6,82. Em relação ao pH afluente, este se mostra mais acidificado, o que é comum devido ao processo anaeróbio. Todavia, mesmo com estas variações, o pH se manteve na faixa de 6 a 9, considerado ideal para o tratamento biológico, por proporcionar melhores condições de existência de maior diversidade biológica.

O pH médio do efluente nos anos do período em estudo, de 6,84 em 2016 e 2018 e de 6,78 em 2017, estão dentro dos limites de lançamento, faixa de 5 a 9, conforme estabelecidos tanto pelas legislações Resolução CONAMA n 430/2011 como pelo Decreto n 1.745/1979 de Goiás.

A temperatura média durante o período analisado possui baixa variabilidade, de acordo com o CV, se mantendo praticamente estável. Entretanto, ao se comparar a temperatura do efluente dos períodos chuvoso e seco, as médias se apresentam diferentes, com a temperatura no período chuvoso maior do que a do período seco, isto se dá porque na região o período de chuvas ocorre durante o verão, onde as temperaturas são mais altas, e o período seco no inverno, onde as temperaturas são baixas.

Mesmo havendo a variação da temperatura, está se encontra dentro da faixa ótima que é de $25^{\circ} \mathrm{C}$ a $35^{\circ} \mathrm{C}$. O que é muito importante para que o tratamento tenha uma boa eficiência, pois a temperatura controla a taxa das reações físico-químicas e biológicas (VON SPERLING, 2005), afeta no desenvolvimento e na atividade dos microrganismos, além de prejudicar a remoção de sólidos ao aumentar a viscosidade do efluente quando a temperatura é baixa (CASSINI, 2008).

A temperatura média do período é de $27,89^{\circ} \mathrm{C}$ estando conforme o padrão de temperatura inferior a $40^{\circ} \mathrm{C}$ estabelecidos pelas legislações estadual (GOIÁS, 1979) e federal (BRASIL, 2011).

\section{DBO e DQO}

A DBO analisada no período em estudo apresentou grande variação, com a DBO afluente e efluente média dos três anos de, respectivamente, $498,61 \mathrm{mg} / \mathrm{L}$ e $64,45 \mathrm{mg} / \mathrm{L}$, como pode ser observado na tabela 7 . 
Tabela 7: Análise de Variancia e Teste de Tukey da DBO da ETE de Caldas Novas/GO.

\begin{tabular}{|c|c|c|c|c|c|c|c|c|}
\hline \multirow{2}{*}{$\begin{array}{l}\text { Análise de variância } \\
\text { GL resíduo }\end{array}$} & \multicolumn{2}{|c|}{$\begin{array}{l}\text { DBO afluente } \\
\left(\mathrm{mgL}^{-1}\right)\end{array}$} & \multicolumn{2}{|c|}{ DBO efluente $\left(\mathrm{mgL}^{-1}\right)$} & \multicolumn{2}{|c|}{ DBO Eficiência (\%) } & \multicolumn{2}{|l|}{$\begin{array}{l}\text { DBO } \\
\left(\mathrm{mgL}^{-1}\right)\end{array}$} \\
\hline & & \multicolumn{2}{|c|}{65} & \multicolumn{2}{|l|}{65} & \multicolumn{2}{|l|}{134} \\
\hline F tratamentos & $20,08^{* *}$ & & \multicolumn{2}{|c|}{$15,96 * *$} & \multicolumn{2}{|l|}{$9,72 * *$} & \multicolumn{2}{|l|}{$98,29 * *$} \\
\hline Média geral & \multicolumn{2}{|l|}{498,61} & \multicolumn{2}{|c|}{64,45} & \multicolumn{2}{|l|}{84,36} & \multicolumn{2}{|l|}{281,53} \\
\hline Desvio padrão & \multicolumn{2}{|l|}{287,19} & \multicolumn{2}{|c|}{25,59} & \multicolumn{2}{|l|}{6,10} & \multicolumn{2}{|l|}{255,35} \\
\hline DMS (5\%) & \multicolumn{2}{|l|}{$(x)$} & \multicolumn{2}{|c|}{$(x)$} & \multicolumn{2}{|l|}{$(x)$} & \multicolumn{2}{|l|}{86,65} \\
\hline $\mathrm{CV}(\%)$ & \multicolumn{2}{|l|}{57,60} & \multicolumn{2}{|c|}{39,70} & \multicolumn{2}{|l|}{7,23} & \multicolumn{2}{|l|}{90,70} \\
\hline \multicolumn{9}{|l|}{ Teste de Tukey a 5\% } \\
\hline & & CV (\%) & & CV (\%) & & & & \\
\hline DBO (2016) & $761,56 \mathrm{a}$ & 57,53 & $71,48 \mathrm{a}$ & 46,06 & $88,60 \mathrm{a}$ & Afluente & 498,61 & $\mathrm{a}$ \\
\hline DBO (2017) & $482,47 \mathrm{~b}$ & 40,41 & $85,11 \mathrm{a}$ & 30,40 & $81,20 \mathrm{~b}$ & Efluente & 64,45 & $\mathrm{~b}$ \\
\hline DBO (2018) & $247,27 c$ & 27,02 & $45,55 \mathrm{~b}$ & 34,51 & $82,40 \mathrm{~b}$ & & & \\
\hline
\end{tabular}

Nível de significância: $1 \% * *, 5 \% *$. (x) Mais de um valor. DMS: Diferença mínima significativa. CV: Coeficiente de variação. Médias com letras iguais entre colunas não se diferem estatisticamente.

A DBO afluente comparada dos três anos, apresentaram valores muito diferentes e coeficiente de variação alto, com médias de 761,56mg/L (2016), 482,47mg/L (2017) e 247,27mg/L (2018). Além disso, a variabilidade também é alta dentro dos anos, indicando diferença discrepante entre os dados. Porém, isso se explica devido à sazonalidade, a qual influência nas características do esgoto em função dos usos à qual a água é submetida, pois, como explica Von Sperling (2005), esses usos e a forma com que são exercidos variam com o clima, situação social e econômica e hábitos da população.

Os valores da DBO efluente, com médias de 71,48mg/L (2016), 85,11mg/L (2017) e 45,55mg/L (2018), também possuem alto coeficiente de variação e consequente grande variabilidade, todavia, com variação entre os dados menor do que o afluente.

A alta variabilidade da DBO efluente é decorrente das diferentes quantidades de matéria orgânica afluente, isso, porque, para que as bactérias responsáveis pelo tratamento biológico tenham melhor desempenho é preciso que haja um ambiente favorável para que elas se desenvolvam, incluindo a quantidade de substrato disponível. Além disso, segundo Viana (2006), em razão da alta concentração de biomassa dentro do reator e o fluxo contínuo, os quais possibilitam a alta atividade dos microrganismos metanogênicos, é possível a aplicação de elevadas cargas orgânicas volumétricas em menores tempos de detenção hidráulica.

A eficiência de remoção teve uma variação baixa, com as médias dos anos 2017 e 2018 consideradas estatisticamente iguais. Essa baixa variabilidade se dá, pois, uma estação de tratamento bem projetada deve manter a estabilidade padrão da eficiência ao ocorrer alterações funcionais, climáticas, entre outros, de acordo com Lobão (2009).

Mesmo com variações, a concentração de DBO efluente, média de $64,45 \mathrm{mg} / \mathrm{L}$, e a eficiência do sistema, média de 84,36\%, estão dentro dos limites estabelecidos pela CONAMA 430/2011 que determina concentração de até $120 \mathrm{mg} / \mathrm{L}$ e eficiência mínima de remoção de 60\% (BRASIL, 2011). Entretanto, referente ao Decreto $\mathrm{n}^{\circ} 1.745 / 1979$ do estado de Goiás, onde se estabelece concentração de até $60 \mathrm{mg} / \mathrm{L}$ e como eficiência mínima 80\% (GOIÁS, 1979), somente a eficiência está em conformidade, pois a concentração se apresenta acima do limite estadual.

Os resultados das análises dos dados de DQO também indicaram variação alta, como pode ser visto 
na tabela 8.

Tabela 8: Análise de Variância e Teste de Tukey da DQO da ETE De Caldas Novas/GO.

\begin{tabular}{|c|c|c|c|c|c|c|c|}
\hline Análise de variância & $\begin{array}{l}\text { DQO afluente } \\
\left(\mathrm{mgL}^{-1}\right)\end{array}$ & & DQO efluente $\left(\mathrm{mgL}^{-1}\right)$ & DQO Eficiência (\%) & $\begin{array}{l}\text { DQO } \\
\left(\mathrm{mgL}^{-1}\right)\end{array}$ & & \\
\hline GL resíduo & 65 & & 65 & 65 & 134 & & \\
\hline F tratamentos & $6,19 * *$ & & $5,92 * *$ & $21,90 * *$ & $56,25 * *$ & & \\
\hline Média geral & 978,42 & & 127,82 & 82,57 & 553,12 & & \\
\hline Desvio padrão & 869,16 & & 45,23 & 6,42 & 661,33 & & \\
\hline DMS (5\%) & $(x)$ & & $(x)$ & $(x)$ & 224,42 & & \\
\hline CV (\%) & 88,83 & & 35,38 & 7,78 & 119,56 & & \\
\hline \multicolumn{8}{|l|}{ Teste de Tukey a $5 \%$} \\
\hline & & CV (\%) & CV (\%) & & & & \\
\hline DQO (2016) & $1.429,9 \mathrm{a}$ & 87,6 & $115,4 \mathrm{~b}$ & 89,32 a & Afluente & 978,42 & a \\
\hline DQO (2017) & $919,77 a b$ & 86,44 & $159,2 \mathrm{a}$ & $78,88 \mathrm{~b}$ & Efluente & 127,82 & $b$ \\
\hline DQO (2018) & $569,15 \mathrm{~b}$ & 29,97 & $117,6 \mathrm{~b}$ & $78,47 \mathrm{~b}$ & & & \\
\hline
\end{tabular}

Nível de significância: 1\%**,5\%*. (x) Mais de um valor. DMS: Diferença mínima significativa. CV: Coeficiente de variação. Médias com letras iguais entre colunas não se diferem estatisticamente.

A DQO afluente, com média geral do período de $978,42 \mathrm{mg} / \mathrm{L}$, apresentou coeficiente de variação muito alto ao se comparar as médias dos três anos, indicando diferença discrepante entre elas. Entretanto, estatisticamente, por meio do Teste de Tukey, as médias 1.429,9mg/L e 919,77mg/L dos anos de 2016 e 2017, respectivamente, são consideradas iguais e as médias de 2017 e a de 2018, 569,15mg/L, também foram consideradas iguais. Além disso, o CV entre os resultados dentro dos três anos também se mostrou alto, indicando grande variabilidade de DQO afluente a ETE.

Referente a DQO efluente, média geral de $127,82 \mathrm{mg} / \mathrm{L}$, as médias dos três do período, $115,4 \mathrm{mg} / \mathrm{L}$ (2016), 159,2mg/L (2017) e 117,6mg/L (2018), também apresentaram grande variação, porém menor comparada ao afluente. Mesmo com variabilidade, o CV das análises de cada ano está próximo ao considerado aceitável para dados de campo.

Com relação a eficiência para a DQO, o sistema obteve eficiência média no período de $82,57 \%$ e variabilidade baixa. O CV baixo indica homogeneidade nos dados, resultado do padrão do sistema no tratamento.

Como as legislações estadual e federal não estabelecem padrões de lançamento para a DQO, fez-se a análise da relação DQO/DBO (tabela 9), pois sabe-se que, essa relação do esgoto bruto doméstico que se situa entre 1,7 e 2,4 vai aumentando ao passar por algum processo de tratamento, indicando eficiência com valores superiores a 3, ou seja, quanto maior a eficiência do tratamento na remoção de matéria orgânica biodegradável, maior essa relação podendo chegar a 4,0 ou 5,0, como explica Von Sperling (2005).

Tabela 9: Análise de Variância e Teste de Tukey da relação DQO/DBO da ETE De Caldas Novas/GO.

\begin{tabular}{llll}
\hline Análise de variância & DQO/DBO afluente & DQO/DBO efluente & DQO/DBO \\
\hline GL resíduo & 65 & 65 & 134 \\
F tratamentos & $4,06^{* *}$ & $24,15^{* *}$ & 1,66 \\
Média geral & 2,04 & 2,20 & 2,12 \\
Desvio padrão & 0,64 & 0,60 & 0,72 \\
DMS (5\%) & $(\mathrm{x})$ & $(\mathrm{x})$ & 0,25 \\
CV (\%) & 31,39 & 27,07 & 34,14 \\
\hline Teste de Tukey a 5\% & & & \\
\hline DQO/DBO (2016) & $1,95 \mathrm{ab}$ & $1,76 \mathrm{~b}$ & Afluente: 2,04 a \\
DQO/DBO (2017) & $1,78 \mathrm{~b}$ & $1,90 \mathrm{~b}$ & Efluente: 2,20 a \\
DQO/DBO (2018) & $2,31 \mathrm{a}$ & $2,85 \mathrm{a}$ & \\
\hline
\end{tabular}

Nível de significância: 1\%**,5\%*. (x) Mais de um valor. DMS: Diferença mínima significativa. CV: Coeficiente de variação. Médias com letras iguais entre colunas não se diferem estatisticamente. 
Como observado na tabela relação DQO/DBO do esgoto afluente a ETE, com média de 2,04 no período em estudo, embora tenha apresentado variação, este se apresenta dentro da faixa considerada típica para esgoto bruto. Esta oscilação é consequente da variabilidade de DBO e DQO afluentes.

Ao analisar a relação DQO/DBO, nota-se que a variabilidade é baixa. Comparando a relação afluente e efluente, percebe-se que não há muita diferença entre elas. Analisando esgoto bruto e tratado, ano a ano, em 2016 a relação apresentou aumento, já em 2017 e 2018 houve aumento, porém este foi baixo.

A relação $D Q O / D B O$ do esgoto tratado durante o período analisado foi de 2,20, ou seja, esta é menor do que o valor $(\mathrm{DQO} / \mathrm{DBO} \geq 3$ ) considerado como indicação de eficiência do tratamento quanto a remoção de matéria biodegradável. Este fato pode ser consequente da atual configuração do sistema, porque, embora segundo Sobrinho et al. (2000) sistemas de Reator anaeróbio seguido de lagoa aerada de mistura completa e lagoa de decantação apresentem muitas vantagens, a lagoa aerada da ETE está sem aerador, ou seja, está operando atualmente como lagoa anaeróbia.

\section{Sólidos Suspensos Totais}

Assim como os outros parâmetros analisados, a análise estatística dos sólidos suspensos totais indicou variabilidade nos dados, conforme dados apresentados na tabela 10.

Tabela 10: Análise de Variância e Teste de Tukey dos SST da ETE De Caldas Novas/GO.

\begin{tabular}{|c|c|c|c|c|c|c|}
\hline Análise de variância & $\begin{array}{l}\text { SST afluente } \\
\left(\mathrm{mgL}^{-1}\right)\end{array}$ & & $\begin{array}{l}\text { SST efluen } \\
\left(\mathrm{mgL}^{-1}\right)\end{array}$ & & SST Eficiência (\%) & $\begin{array}{l}\text { SST } \\
\left(\mathrm{mgL}^{-1}\right)\end{array}$ \\
\hline GL resíduo & 65 & & 65 & & 65 & 134 \\
\hline $\mathrm{F}$ tratamentos & 2,83 & & 0,43 & & 3,55 & $64,32 * *$ \\
\hline Média geral & 149,23 & & 24,11 & & 77,43 & 86,67 \\
\hline Desvio padrão & 124,17 & & 17,17 & & 17,29 & 90,97 \\
\hline DMS (5\%) & $(x)$ & & $(x)$ & & $(x)$ & 30,87 \\
\hline CV (\%) & 83,20 & & 71,24 & & 22,33 & 104,96 \\
\hline \multicolumn{7}{|l|}{ Teste de Tukey a 5\% } \\
\hline & & CV (\%) & & CV (\%) & & \\
\hline SST (2016) & $115,88 a$ & 112,23 & 21,80 a & 93,78 & $70,42 \mathrm{~b}$ & Afluente: $149,43 \mathrm{a}$ \\
\hline SST (2017) & $206,07 a$ & 81,76 & $26,64 a$ & 59,40 & $83,91 \mathrm{a}$ & Efluente: $24,11 \mathrm{~b}$ \\
\hline SST (2018) & $141,66 \mathrm{a}$ & 48,58 & 24,59 a & 58,00 & $79,77 \mathrm{ab}$ & \\
\hline
\end{tabular}

Nível de significância: $1 \% * *, 5 \% *$. (x) Mais de um valor.

Ao que diz respeito ao SST afluente, os coeficientes de variação indicam diferença significante da concentração medida ao longo dos anos e em análise de comparação entre as médias anuais obtidas no período em estudo. Esta variação se dá pois, assim como a concentração de DBO afluente, a quantidade de sólidos no esgoto bruto é influenciada pelos fins ao qual a água é submetida, de acordo com a economia, épocas do ano e os costumes da população.

Com média do período de $24,11 \mathrm{mg} / \mathrm{L}$ a concentração de SST do esgoto tratado também apresentou CV alto, o que indica alta variabilidade, entretanto não houve diferença significativa entre elas.

Quanto a eficiência, mesmo o CV indicando grande variação, esta é menor a comparada com as variações obtidas entre os dados afluente e efluente. Entre elas, estatisticamente, as médias das eficiências dos anos 2016 e 2018 são iguais e a média de 2018 é igual a de 2017, ou seja, elas estão próximas dentro da distribuição normal. 
As legislações estadual e federal não estabelecem padrões lançamento para os sólidos totais suspensos, porém a eficiência média do sistema no período em estudo equivalente a 77,43\%, está dentro da faixa de 65 a $80 \%$ de remoção do reator anaeróbio conforme dito da literatura e de média de até $80 \%$ de remoção após passar pelos tratamentos preliminar a secundário (TARDIVO, 2009).

\section{CONCLUSÕES}

Devido à alta variabilidade nos dados, houve influência da sazonalidade quanto a contribuição à estação, pois, como a economia do município é voltada para o turismo, tanto a população flutuante quanto as mudanças climáticas interferem na característica do esgoto.

Conclui-se também que, durante o período analisado, a ETE apresentou bom desempenho por meio dos resultados satisfatórios quanto aos parâmetros analisados, $\mathrm{pH}$, Temperatura e DBO, que obtiveram valores dentro dos limites exigidos pela legislação estadual, Decreto $n^{\circ}$. 1.745/1979 e também legislação federal Resolução CONAMA 430/2011.

Referente a DQO, como a legislação não estabelece padrões para seu lançamento fez-se a análise da relação DQO/DBO. Embora o sistema tenha apresentado boa eficiência de remoção da DQO, por meio do resultado da relação, nota-se que o sistema não demonstrou boa eficiência no que diz respeito a remoção de matéria biodegradável.

Quanto aos SST, a ETE obteve eficiência satisfatória, mesmo não havendo padrões estabelecidos pelas legislações estadual e federal para este parâmetro, este se apresentou de acordo com as eficiências encontradas na literatura.

\section{REFERÊNCIAS}

AMAT. Associação das Empresas Mineradoras das Águas Termais de Goiás. Meteorologia da região. Caldas Novas: AMAT, 2019.

APHA; AWWA; WPCF. American Public Health Association. American Water Works Association. Standard Methods for the Examination of Water and Wastewater. $18 \mathrm{ed}$. New York: Public Heart Association Inc., 1998.

ABNT. Associação Brasileira de Normas Técnicas. Norma NBR 9648/1986: Estudo de concepção de sistemas de esgoto sanitário - Procedimento. Rio de Janeiro: ABNT, 1986.

ABNT. Associação Brasileira de Normas Técnicas. Norma NBR 9898/1987: Preservação e técnicas de amostragem de efluentes líquidos e corpos receptores - Procedimento. Rio de Janeiro: ABNT, 1987.

BARBIERO, L. C. S.; LEMES, E. S.. A influência das estações do ano no consumo de água em Maringá-PR. Revista Percurso: NEMO, Maringá, v.3, n.1, p.183-191, 2011.

BRASIL. Ministério do Meio Ambiente. Conselho Nacional do Meio Ambiente. Resolução CONAMA n. 430, de 13 de maio de 2011. Dispõe sobre as Condições e Padrões de Lançamento de Efluentes Complementa e Altera a Resolução no 357 de 17 de março de 2005. CONAMA, 2011.
CASSINI, A. S.. Estudo de processos alternativos no prétratamento de efluentes provenientes da produção de isolados proteicos. Tese (Doutorado em Engenharia) Universidade Federal do Rio Grande do Sul, Porto Alegre, 2008.

COSTA, R. A.; SILVA JÚNIOR, C. C.; SANTOS, F. O.. O uso de geoindicadores na avaliação da qualidade ambiental da cidade de Caldas Novas (GO). In: SIMPÓSIO REGIONAL DE GEOGRAFIA - EREGEO, 10. Anais. Catalão: UFG, 2007.

COSTA, R. A.; NISHIYAMA, L.. Zoneamento ambiental das áreas urbana e de expansão urbana de Caldas Novas (GO): uma contribuição metodológica. Raega: O Espaço Geográfico em Análise, v.25, 2012. DOI: http://dx.doi.org/10.5380/raega.v25i0.28016

DEMAE. Departamento Municipal de Água e Esgoto de Caldas Novas/GO. Plano municipal de saneamento básico De Caldas Novas (GO): referente às prestações dos serviços de abastecimento de água potável e de esgotamento sanitário. Caldas Novas: DEMAE, 2018.

GOIÁS. Superintendência do Meio Ambiente. Decreto n. 1.745, de 06 de dezembro de 1979. Aprova o Regulamento da Lei n. 8.544 de 17 de outubro de 1978, que dispõe sobre 
a prevenção e o controle da poluição do meio ambiente. Goiânia: Superintendência do Meio Ambiente, 1979.

HANAI, F. Y.; CAMPOS, J. R.. Avaliação da infiltração na rede coletora de esgotos na bacia do Ribeirão do Ouro da cidade de Araraquara, SP. In: CONGRESSO BRASILEIRO DE ENGENHARIA SANITÁRIA E AMBIENTAL. Anais. Foz do Iguaçu, 1997.

LOBÃO, J. R. S.. Análise de desempenho, estabilidade e confiabilidade de estações de tratamento de esgoto. Dissertação (Mestrado) - Universidade Federal do Ceará, Fortaleza, 2009.

NUVOLARI, A.. Esgoto sanitário: coleta, transporte, tratamento e reuso. 2 ed. São Paulo, 2003.

OLIVEIRA, D. I. S.. Impacto de variáveis meteorológicas nos padrões de consumo de água no noroeste de Portugal. Tese (Mestrado integrado em Engenharia Civil) -Universidade do Moinho, Porto, 2014.

PRADO, T. M. R.; GOMES, N. G. U.; FERREIRA, W. R.. O Estudo da Relação Intrínseca entre o Trânsito e o Turismo na Cidade Caldas Novas-GO. Geoambiente, n.11, p.01-18, 2008. DOI:

http://doi.org/10.5216/rev.geoambie.v0i11.25977
ROCHA, A. L.. Sazonalidade de Demanda Turística: hotéis de pequeno porte de caldas Novas (Goiás). Monografia (curso de Especialização em Hospitalidade) - Universidade de Brasília, Brasília, 2003.

SOBRINHO, P. A.; JORDÃO, E. P.. Pós-tratamento de efluentes de reatores anaeróbios: uma análise crítica. In: Pós-tratamento de Efluentes de Reatores Anaeróbios: Rede de Pesquisas formada no âmbito do Edital 02 do Programa em Saneamento Básico (PROSAB). 2000. p.1-17.

TARDIVO, M.. Considerações sobre o monitoramento e controle dos parâmetros físicos, químicos e biológicos de estações de tratamento de esgotos e proposta para sistema integrado de gestão com enfoque ambiental, controle de qualidade, segurança e saúde. Tese (Doutorado) Universidade de São Paulo, São Carlos, 2009.

VIANA, A. B.. Tratamento anaeróbio de vinhaça em reator UASB operado em temperatura na faixa termofílica $\left(55^{\circ} \mathrm{C}\right)$ e submetido ao aumento progressivo de carga orgânica.

Dissertação (Mestrado) - Escola de Engenharia de São Paulo, Universidade de São Paulo, São Carlos, 2006.

VON SPERLING, M.. Introdução à qualidade das águas e ao tratamento de esgotos. Princípios do tratamento biológico de águas residuárias. 3 ed. Belo Horizonte: Universidade Federal de Minas Gerais, 2005.

A CBPC - Companhia Brasileira de Produção Científica (CNPJ: 11.221.422/0001-03) detém os direitos materiais desta publicação. Os direitos referem-se à publicação do trabalho em qualquer parte do mundo, incluindo os direitos às renovaç̃̃es, expansões e disseminações da contribuição, bem como outros direitos subsidiários. Todos os trabalhos publicados eletronicamente poderão posteriormente ser publicados em coletâneas impressas sob coordenação da Sustenere Publishing, da Companhia Brasileira de Produção Científica e seus parceiros autorizados. Os (as) autores (as) preservam os direitos autorais, mas não têm permissão para a publicação da contribuição em outro meio, impresso ou digital, em português ou em tradução. 